\title{
Research on the Development of Daur Ethnic Education under the Influence of Big Data
}

\author{
Chuangang $\mathrm{Wu}^{1}$ \\ ${ }^{1}$ MuDanJiang Normal University, \\ MuDanJiang City, HeiLongJiang Province,China \\ 157011
}

\author{
Lei Wang ${ }^{1}$ \\ ${ }^{1}$ MuDanJiang Normal University, \\ MuDanJiang City, HeiLongJiang Province,China \\ 157011
}

\author{
Jiaojiao Qu ${ }^{1}$ \\ ${ }^{1}$ MuDanJiang Normal University, \\ MuDanJiang City, HeiLongJiang Province,China 157011
}

\begin{abstract}
In this paper, we conduct research on the development of Daur ethnic education under the influence of big data. Life in the river valley of Daur ethnic which is a nationality has a long history, splendid culture and the national spirit of national self-confidence, the foundation of national culture has a strong self-confidence. Combining the concept of big data and data analysis technique to the Daur ethnic education will largely enhance the result of the current education pattern. The survey of the research indicated that we should pay attention to the precious data captured.
\end{abstract}

Keywords: Daur Ethnic; Big Data; Education Development; Review and Survey.

\section{Introduction}

National culture development and prosperity without cultural self-confidence and self-awareness, minority cultural heritage should be established on the basis of cultural self-confidence. Only a nation established firmly confident of the own culture which can make its cultural heritage conscientiously. Cultural self-confidence, will tell from the essence is one kind of aware psychological identity, firm faith and correct cultural point of view, is the ability to understand and agree with their own cultural connotation and value, and confidence in the cultural vitality and development prospects. Life in the river valley of Daur ethnic which is a nationality has a long history, splendid culture and the national spirit of national self-confidence, the foundation of national culture has a strong self-confidence. Under new historical conditions, the national cultural confidence will become the important foundation of national cultural inheritance and conditions. Daur is the minority nationalities in the north of our country, though the term of Ming Qing dynasty is recorded in the history books, but the ancient descendants of the nationality, its national history can be traced back to the established. After the Qing dynasty set up to get friendly with the Manchu rulers, the Daur people who have repeatedly to ruler to the rich, but the Manchu rulers launched the war from conquering many times, this makes the Daur people's production and living are being destroyed, is also a large number of population. But the war did not make the Daur people succumb to their indomitable perseverance survived. Education is the most important heritage of human civilization, the most effective tools, also is the cradle of the development of modern culture. Modern education has multiple functions, also provides the Daur culture premise and possibility. The party and the government's national education policy for the development of the national school have provided a broad space. University for nationalities, ethnic middle school, elementary school, according to the need to set up in all parts of the country, greatly satisfy the 
desire to minority people accept education. Through the national schools at various levels and of passing on national culture, is the most important ways of national culture to thrive. The characteristics of the education total. Modern education is for the national education, the implementation of the nine-year compulsory education, let the Daur children accept education of the whole. Through the school learning, inherit the excellent cultural tradition, grasp the advanced science and culture and cultivate the national spirit of modern people. Make the national culture into the campus, into the students, national culture is the survival and development of expansive soil. Any calls on sex, training, social cultural cultivation mode has the characteristics of narrow, short-term, erosion, and curing, inherit and promote function of education is unmatched [1-2].

In this paper, we conduct research on the development of Daur ethnic education under the influence of big data. Education is the enlightenment the dynamic process of development, mental health, has the characteristics of generative. National culture education must grab from baby, by infection, infiltration, teach and experience, make a new generation of Daur grows with strong national culture, national spirit into the children of the flesh and spirit. Ethnic culture only with the student growth and growth will have vitality. Big data influence on education is multi-dimensional and will be more deeply. The traditional education anthropology research areas will be covered with big data. We study the Qiqihaer city in Heilongjiang province the $M$ ethnic primary school from the perspective of big data affect the national language and the problems of cultural inheritance and a new solving strategy. In the following sections, we will discuss the issues in detail with theoretical discussion.

\section{The Principles of Our Survey}

The Situation of Daur Language Usage. Daur in Heilongjiang province mainly residential area in the city the Qiqihar including five Daur district is the city governs ethnic area only the Daur in the area. But now we will say of Daur language and understand the people of the Daur traditional culture gradually reduce, language cultural inheritance faces many problems. Our research has chosen the Daur ethnic school of Hala Xincun and here is what we call M primary school [3]. The school has strong representative in our research. Era in the development of national education in the new historical development period, inclusive and integrated national school is also growing, metabolic function is also rising. Two outstanding performance: a full national faculty of school teachers composition occupied the main part is no longer, the Han nationality staff ratio increased rapidly, even accounting for the main body, this is also the development of history. Trends, such as Qiqihaer city, Qiqihaer city Daur ethnic middle school high school, greater China hui nationality elementary school has the characteristics such as Qiqihaer city built and it is the practice of ethnic school only recruits students have become the past, and for education "to the" raw, the new situation of the reform of school to survive and development, must face all, of the national student recruit students, Han ethnic school students as the main body has become a reality. Because the nation is to have a common language, common geography, common economic life, the common cultural characteristic, the common psychological quality and the stability of the community, common culture and psychological quality is essential for the formation of elements. As members of the ethnic groups, namely the body of the national culture, acknowledge and are willing to inherit and carry forward the national culture is the national cultural identity. A nation to bring outstanding cultural heritage, first of all to promote national members agree with the consciousness of national culture, the formation of strong national sentiment. The Daur excellent culture heritage which also depend on the national members to our national cultural identity, based on this to maintain the most basic 
cultural elements and the development of the national excellent culture [4-5].

With the rapid development of economic and social, cultural variation or disappear speed is accelerated, a lot of the crisis of cultural identity of ethnic minorities. To enhance the young generation of Daur ethnic identity of their native culture, should be in-depth excavation of the deep cultural connotation of the Daur nationality. Although the Daur students for this national culture cognition, but for more positive emotion performance, our culture is very love the Daur culture, has a deep understanding of our culture appeal and curious feeling, which in turn generate intense yearning and pride. Our finding will be illustrated in the next section.

The Result of the Survey and Research. In the following parts, we conclude the finding from the survey. (1) Low degree of Daur student mastery of language. Daur nationality is a typical language without words of ethnic minorities and the inheritance of aur language mainly through word of mouth, however due to intermarry and urbanization, the influence of such factors as the word of mouth in this form lost family education carrier between family members is now rarely used Daur language to communicate which make the most of the students became the localization of the Daur people. The survey result indicates that $51 \%$ students could neither understand nor speak, 39\% of them could just understand but unable to speak. Only the rare $10 \%$ could speak and understand. (2) Daur students are not optimistic and understanding of national customs and habits. Daur ethnic population is less but it is rich in national culture and living habits, but the Daur school pupils to understand Daur ethnic traditional culture degree is very low. $69 \%$ of the students don't know too much for Daur traditional culture said, $73 \%$ of the students said the Daur history said. Countries compile for universal use textbooks used in school education at present, only a few larger minority culture reflected in the teaching material, to a population less minorities such as Daur is less than. This requires that we must think seriously about how to in the school education of Daur populated areas better melt of Daur culture education. National schools have a duty to factor into the national culture in the school education, the school management and general operation, curriculum, teaching, education evaluation and so on permeability, national customs and national spirit makes the national culture in Daur school education occupies a certain position, to facilitate the smooth transmission of national culture. First, the students should be told the knowledge goals. According to the survey of the Daur students of national cultural identity, according to the results of the student legend for this nation's history, origin, etiquette, taboo, the traditional process, less understanding of language, singing and dancing, the knowledge of the school-based curriculum goal orientation in helping Daur students deep understanding of the knowledge representation of our culture and the profound spiritual connotation, make its full and accurate, system in-depth knowledge of the traditional culture of Daur. Second is the ability to target. Survey, daur students of this national culture has a positive emotional experience, more love the Daur culture, but on the behavioral intention is very difficult to comply with the national customs and habits, as a result, the ability of school-based curriculum aims at improve the Daur students to our national cultural adaptability and practical ability, to be able to apply the dialectical, critical thinking, analysis the characteristics of the different culture, so as to enhance the cultural choice. (3) The lack of professor Daur language teachers and research strength. In the following table, we show the age distribution of the teachers.

Table 1. The Age Distribution of the Teachers

\begin{tabular}{|c|c|c|c|c|}
\hline Age & $20-30$ & $31-40$ & $41-50$ & $>50$ \\
\hline Amount & 2 & 5 & 6 & 9 \\
\hline
\end{tabular}


Daur school-based curriculum construction cannot indiscriminately absorbed all kinds of culture, also cannot abandon all to be selectively which should be to do a good job of screening of national culture, the excellent national cultural resources into school-based curriculum content system. The development of national culture course should combine the modern education concept, in accordance with the national education policy. Daur shamanism is the religion, literature, art, music, dance, carrying a long national culture, is the most basic, the most core part of the traditional culture, as a nation most representative shamanism culture symbol, used to strengthen the national identity consciousness, easy to accept by people. Comprehensive consideration all aspects of the views and opinions, multivariate analysis of evaluation subject, diagnosis, and the helpful to get more objective evaluation information. Especially the Daur culture of the construction of the evaluation of the school-based curriculum experts and scholars do not deflect improve students are the subject of the national cultural identity, make the development of school-based courses focus on ethnic cultural change and development, and constantly improve, changes to the plan on the development of school-based curriculum, so as to maintain national culture characteristic to promote the development of school-based curriculum dynamic.

The Conclusion from the Survey and the Prospect. Teaching of biphasic law requires that we must pay attention to the thoughts and feelings and information exchange between teachers and students. Want to feelings of harmony between teachers and students and we must from the national student's personality, hobbies, interests and habits, to carry out the education teaching activities. Among them, the national language and words in two-way activity plays an important role. National language is the carrier of national culture, is the national feelings, to promote national identity which is a powerful tool to meet the need of national cultural psychology. Daur is a language without words.
In the teaching activities, teachers must consider appropriate and reasonable use of Daur language problem. Of course, there are many teachers, especially old teacher in the classroom teaching attempt in this regard. Therefore, we put forward the following suggestions to help modify the current pattern of education. (1) Data of infiltration to solve the fund shortage opens up a new way of thinking. If we want the Daur language go down, must involve teaching equipment, teaching materials, teaching materials development, funds investment is necessary but these depend on the traditional way is difficult to solve. Big data way of infiltration has saved a huge research funds which can be directly transferred to the construction of network equipment. (2) The data show the life pattern. In the process of inheriting Daur ethnic cultural heritage, family atmosphere edification and between family members which have intention to not intentional of influence has a key role. But ignoring the non-mainstream culture and desalination makes youth generation of inheritance lost confidence. When we use the network to the beauty of national life, it would rich in data transmission when displayed. Improper can get more recognition and also can enhance the confidence of the ethnic cultural inheritance. (3) Data will help the interaction of teachers. Quality promotion and development of teachers need a development and exchange platform. And relatively closed area, and limited the communication with the outside world, information input, the output is insufficient. Build up a network interactive platform for teachers to communicate, can communicate with other parts of the national teacher and will deepen the study of ethnic language and culture teachers. At the same time can solve trainings in culture and geographical limitations. All in all, the big data technique will help the teachers to teach more effectively. 


\section{Conclusion}

In this paper, we conduct research on the development of Daur ethnic education under the influence of big data. Daur is the minority nationalities in the north of our country, though the term of Ming Qing dynasty is recorded in the history books, but the ancient descendants of the nationality, its national history can be traced back to the established. Teaching of biphasic law requires that we must pay attention to the thoughts and feelings and information exchange between teachers and students. With the rapid development of economic and social, cultural variation or disappear speed is accelerated, a lot of the crisis of cultural identity of ethnic minorities. In the future, we will research on more applications of big data to the area of education to accelerate the process of higher quality education.

\section{Acknowledgements}

This paper is financially founded by the humanities and social science project in Heilongjiang province department of education funding (NO. 12522309). The project name is: education of Heilongjiang province from the anthropological studies of Daur ethnic education.

\section{References}

[1] Yan-hua, J., \& Hua, W. (2014). The inheritance and innovation of daur folk dance. Journal of Qiqihar University.

[2] Jing-xin W, Ai-wen N. The Research about Daur Traditional Cultural Inheritance and Education— Take Xinjiang Tacheng Axier Daur Nationality Township as an Example[J].

[3] Qingxia D, Yan D. The Historical Evolution of Bilingual Education for China's Ethnic Minorities[J]. Chinese Education \& Society, 2014:7-53.

[4] Xi-hui, L. (2014). Multicultural characteristics of ethnic education and employment of ethnic minority students. Journal of Research on Education for Ethnic Minorities.

[5] Wen-bo, C., Jie, M., College, T., \& University, S. (2014). Statistical analysis of literatures of ethnic education in china. Journal of Research on Education for Ethnic Minorities. 